\title{
Chronic fatigue syndrome in children: a cross sectional survey
}

\author{
M X Patel, D G Smith, T Chalder, S Wessely
}

Arch Dis Child 2003;88:894-898

See end of article for authors' affiliations ....................

Correspondence to: Dr D G Smith, Malagay Barn, Church Road, West Tilbury Village, Essex RM18 8TU, UK: mecfsdgs@aol.com

Accepted

16 January 2003
Background: Chronic fatigue syndrome (CFS) in children is a controversial diagnosis with unclear aetiology, ill defined but likely increasing incidence, and debatable clinical management options. However these children experience real and considerable suffering. Appropriate research in this clinical population is sparse and usually occurs in tertiary referral units.

Methods: Cross sectional survey of 36 children attending a GP specialist interest clinic in southeast England.

Results: Patient sociodemographics and clinical morbidity were largely comparable to the literature from tertiary referral research centres. Some prognostic indicators for adults did not readily transfer to this younger age group, although several children had a positive family psychiatric history. Receiving treatment was associated with increased school attendance, but one third of subjects obtained no qualifications. Return to normal health or significant overall improvement was reported by $29 / 36$ subjects.

Conclusions: The outcomes in this setting are favourable and comparable to those seen in a controlled setting; this study supports the concept that the prognosis for CFS in children and adolescents is generally good. However, the impact of the illness is significant and this is perhaps most evident in terms of education. Current methods of reporting educational outcomes in the literature are varied and merit development of standardised tools.
$\mathrm{T}$ he definition of chronic fatigue syndrome (CFS) in children is usually taken to be the same as that for adults, ${ }^{12}$ although the criterion of a six month duration is considered by some as too long for children. ${ }^{34}$ Prolonged school absenteeism is also occasionally included in the definition as a proxy measure for functional impairment and severity. ${ }^{5}$ Epidemiological studies for CFS in children are sparse, ${ }^{6}$ although in the Netherlands, the prevalence in teenagers has been reported as 10-20 per 100000 inhabitants. ${ }^{5}$ In Australia, eight of 42 CFS cases were found to be under the age of $15 .{ }^{7}$ More recently, in a community survey of nearly 4000 children in the USA, $2 \%$ were found to have had CFS-like illness. ${ }^{8}$ Existing epidemiological data for children in Great Britain is mainly founded on small scale studies, and thus it has been concluded that the exact dimensions of the problem remain unclear. ${ }^{910}$

In CFS, symptom occurrence in children is similar to that seen in adults, ${ }^{11}$ and most commonly includes: muscle ache, sore throat, headache, abdominal pain, increased somnolence, concentration difficulties, ${ }^{12-16}$ and depression. ${ }^{17}$ Most children with CFS also display an impaired school performance and a decrease in social activities. ${ }^{13}{ }^{16}$ However, children seemingly differ from adults with earlier presentation and a more optimistic outcome. In a systematic review, ${ }^{18}$ four studies on children with CFS showed that $54-94 \%$ of children recovered. In this age group, good prognostic indicators include specific physical triggers to the illness, start of illness in the autumn school term, and higher socioeconomic status. ${ }^{19}$ Alternatively, important factors in the persistence of fatigue include somatic attributions ${ }^{5}$ or attributions to biological processes, ${ }^{20}$ as well as illness enhancing cognitions and behaviour of parents as well as physical inactivity. ${ }^{5}$

Children with CFS have been successfully treated in secondary and tertiary referral units. ${ }^{19}$ The literature suggests that these children should be treated with a multifactorial approach; this usually includes a graded behavioural programme, with an additional graded approach for return to school, which is sometimes combined with family therapy. ${ }^{621}$ Attention should be paid to psychosocial factors, working with the family to encourage more activity, decreasing attention to somatic complaints, and reducing illness behaviour. Disruption to education, social, recreational, and peer group integration should be minimised. 'The use of antidepressants in children has been advocated, ${ }^{6}$ where depression is a significant feature (as often seen in CFS), based on evidence provided. $^{21} 22$

Unfortunately, CFS in children has received much adverse publicity. The very essence of diagnosis and the clinical labelling of such children has been questioned..$^{23-25}$ Even effective management options have been ridiculed. However, there has been recent widespread concern about an apparent increase in CFS in children. ${ }^{9}$ The impact of this illness is profound as one survey suggested that CFS is responsible for $50 \%$ of long term absences from school. ${ }^{26}$ There is also the frequently repeated assertion that the mean length of illness in childhood is approximately five years. ${ }^{27}$ It is against this undesirable backdrop that we detail a cross sectional study reporting on degree of disability and symptomatology in a GP specialist interest clinic for CFS. Further, prognostic indictors in children with CFS are considered.

\section{METHODS}

Design

Using a cross sectional design, all eligible patients were sent a battery of standardised questionnaires by post. Further data were later obtained from the clinical notes and a follow up telephone call.

Abbreviations: CFS, chronic fatigue syndrome; GHS, General Health Questionnaire; GP, general practitioner; HAD, Hospital Anxiety and Depression scale 


\section{Clinic description}

DGS runs a general practitioner (GP) specialist interest clinic in chronic fatigue syndrome for assessment and treatment of patients of all ages in southeast England. On average, he sees one hundred new National Health Service patients per year. Two thirds of these patients reside in the areas of Sussex, Kent, East London, and Essex. The majority are referred directly by the patient's GP and approximately one third of patients are referred directly by consultants. No referred patients are too ill to travel to the clinic and none are private referrals.

Initial assessment clinical interviews, including screening for anxiety and depression, are followed by a standard battery of clinical investigations. Treatment entails engagement, education, and medication (antidepressants of low to average dose). Further psychological aspects of treatment, which primarily involve an individualised modified activity programme for both mental and physical activity, address the following factors:

- Discussion regarding stressors

- Normalisation of sleep pattern (sleep hygiene)

- Structured graduated daytime activity programme with self identified goals

- Graduated stepwise reintroduction to previous main daytime activity (for example, schooling)

- Development of non-maladaptive coping strategies for anxiety.

For the first 6-9 months, patients are reviewed on a monthly basis followed by two-monthly appointments. The average length of treatment duration is two and a half to three years.

\section{Subjects}

All children aged 18 or less, who were patients currently receiving treatment in summer 1998 or who had completed treatment in the previous 12 months were included in this study. The only exclusion criterion was a primary diagnosis other than chronic fatigue syndrome.

\section{Measures}

The battery of standardised questionnaires included the following outcome measures:

- Fatigue Questionnaire. ${ }^{28}$ Eleven fatigue items are scored on a four-option continuum from "less than usual" to "much more than usual". Ratings are coded using a bimodal method, with caseness being defined as a minimum score of 4 (range $0-11$ ).

- General Health Questionnaire (GHQ), 12 item. ${ }^{29}$ Twelve depression and anxiety items are rated on the same four options as used in the fatigue questionnaire. Ratings are coded using a bimodal method with a cut off of 4 indicating psychological caseness (range 0-12).

- Social adjustment scale. ${ }^{30}$ Impairment in work, home management, social activities, and private leisure are rated on scales from 0 (no impairment) to 8 (maximal impairment). The subscales of work and home management were adapted to school and home life measures, deemed more suitable for children. Scores were summated to give a total score of function of "work" and social ability.

- Hospital Anxiety and Depression scale (HAD). ${ }^{31}$ Fourteen depression and anxiety items are rated on by three individual options per item relating to severity of the symptom. Subscale scores are calculated for depression and anxiety respectively (subscale ranges 0-17 each). Subscale scores greater than 11 are defined as reaching caseness.

- Fear questionnaire. ${ }^{32}$ Twenty items are rated on scales from 0 (no avoidance) to 8 (total avoidance). Scores are calculated for five-item subscales of agoraphobia, blood, social, and dysphoria (subscale ranges 0-40 each) as well as a total aggregate score (range $0-100$ ).
- Symptom checklist. ${ }^{33}$ Forty common symptom items scored as being present or not present within the previous week. An aggregate total score of all the affirmative answers is calculated (range 0-40).

- Attribution scale. ${ }^{34}$ Nine attribution items scored as "not a factor", "might be a factor", or "definitely a factor" and are coded individually.

- Patient satisfaction. ${ }^{35}$ Sixteen items concerning satisfaction with various aspects of treatment, including the clinicianpatient relationship, are scored as occurring or not occurring, and also on a five-point Likert scale for degree of usefulness. Items are coded on an individual item basis.

- Global outcome measure. ${ }^{34}$ Five items measuring global improvement, satisfaction with treatment outcome, degree of handicap (restriction), improvement in fatigue, and usefulness of treatment are measured with the first four factors on a seven-point scale and the latter on a five-point Likert scale with individual options per item. Low scores indicate significant improvement. Ratings are collapsed into dichotomous categories with scores of 1-3 (representing significant improvement/usefulness/satisfaction), and scores of 3 or more (representing deterioration/uselessness/ dissatisfaction).

Additionally, questions on demographic data, school attendance, benefits, and alcohol intake were included.

\section{Procedure}

Subjects were identified by the clinic database and were sent the battery of standardised questionnaires by post. Patient consent was taken as implicit on return of completed questionnaires. Further data were obtained from the clinical notes including diagnosis, medication used, and duration of treatment. Eighteen months later, a follow up telephone call was made to further identify educational outcome data, for example, number of GCSEs achieved. Data were analysed using SPSS software.

\section{RESULTS}

\section{Sociodemographic data}

Thirty six of 40 children and their parents responded to our questionnaires $(90 \%)$. Table 1 shows the sociodemographic details.

\begin{tabular}{|c|c|c|c|}
\hline & $\mathrm{n}$ & $\%$ & \\
\hline \multicolumn{4}{|l|}{ Sex } \\
\hline Male & 11 & 30.6 & \\
\hline Female & 25 & 69.4 & \\
\hline \multicolumn{4}{|l|}{ Ethnicity } \\
\hline White/British & 35 & 97.2 & \\
\hline White/European & 1 & 2.8 & \\
\hline Other & 0 & 0.0 & \\
\hline \multicolumn{4}{|c|}{ Standard occupational classification of parents ${ }^{36}$} \\
\hline Level 4 & 12 & 33.3 & \\
\hline Level 3 & 15 & 41.7 & \\
\hline Level 2 & 7 & 19.4 & \\
\hline \multirow[t]{2}{*}{ Level 1} & 2 & 5.6 & \\
\hline & Mean & SD & Range \\
\hline Age (years) & 15.92 & 1.59 & $11-18$ \\
\hline No. of months pre-presentation & 27.2 & 19.9 & $3-77$ \\
\hline Total no. of months in treatment & 24.4 & 17.1 & $4-76$ \\
\hline
\end{tabular}

Occupations are classified in terms of their skill as defined by the nature and duration of the qualifications, training, and work experience required for competency in tasks of a particular job. Leve 4 relates to professional occupations and managerial positions; leve 3 includes technical occupations and a variety of trade occupations; level 2 includes machine operation, caring, and clerical occupations: level 1 includes cleaners, porters, and catering assistants. 


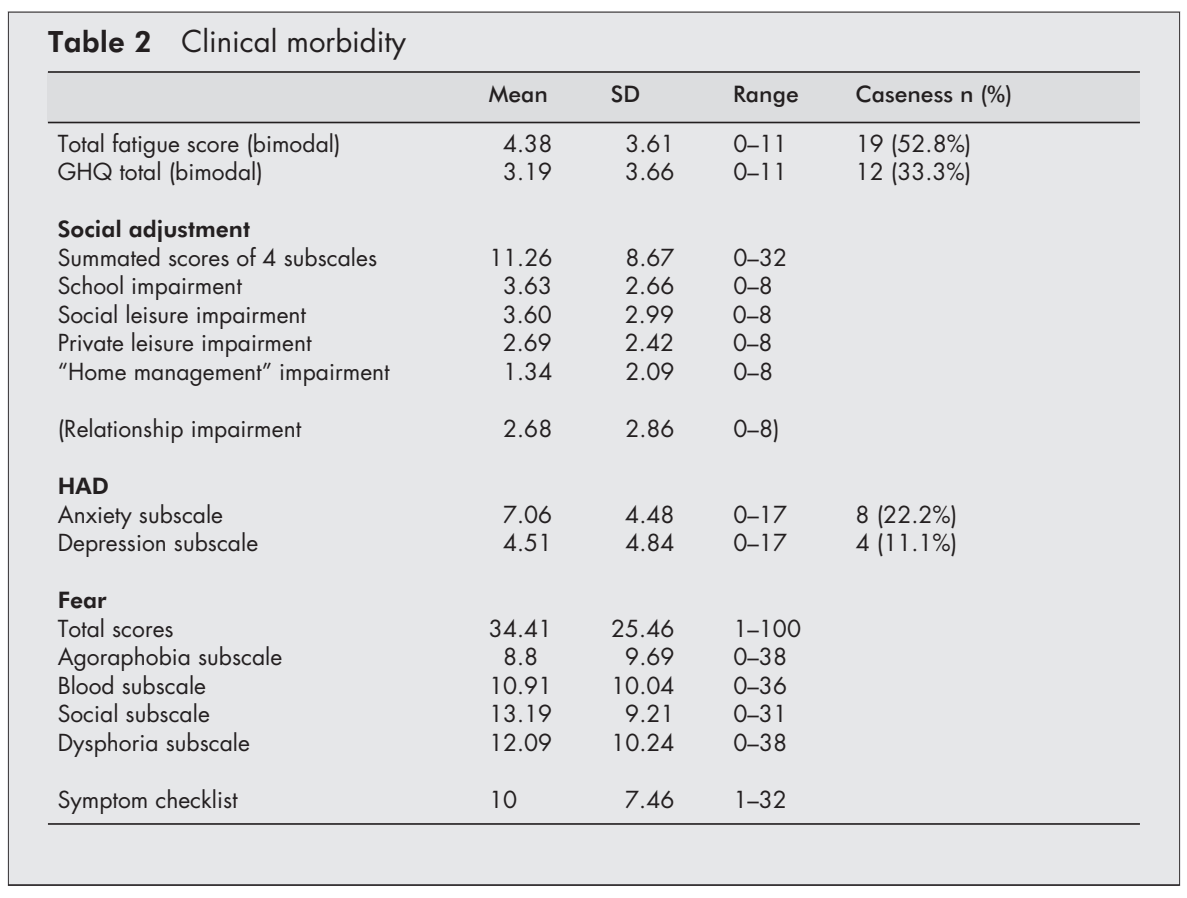

\section{Clinical morbidity}

The onset was reported to be uncertain by 27 children (75\%). At the time of this cross sectional survey, 12 children (33.3\%) reported fatigue lasting less than six months, and nine children (25\%) reported fatigue of six months or more, with 15 children $(41.7 \%)$ not reporting duration of fatigue. Table 2 details the findings for the main measures of fatigue, GHQ, social adjustment, HAD scale, and fear. Co-morbid syndromes of anxiety $(n=11,30.6 \%)$, stress related $(n=6,16.7 \%)$, social phobia $(\mathrm{n}=2,5.6 \%)$, depression $(\mathrm{n}=1,2.8 \%)$, and physical disease $(n=3,8.3 \%)$ were detected, with 15 children $(41.7 \%)$ being free of co-morbid syndromes.

\section{Symptom checklist}

The most commonly reported symptoms were: headaches $(\mathrm{n}=28,77.8 \%)$, daytime drowsiness $(\mathrm{n}=22,61.1 \%)$, sore throat $(\mathrm{n}=17,47.2 \%)$, eyestrain $(\mathrm{n}=17,47.2 \%)$, stomach pain $(\mathrm{n}=15,41.7 \%)$, dry mouth $(\mathrm{n}=14,38.9 \%)$, back pain $(\mathrm{n}=14,38.9 \%)$, joint pain $(\mathrm{n}=14,38.9 \%)$, muscle pain $(\mathrm{n}=14,38.9 \%)$, and stiffness in limbs $(\mathrm{n}=12,33.3 \%)$.

\section{Prognostic indicators}

Five (13.9\%) children had a positive family history of chronic fatigue syndrome in a first degree relative. Nine $(25.0 \%)$ had a positive psychiatric family history in a first degree relative: five parents, two siblings, and two (of the same family) were all first degree family members. Only four (11.1\%) of the children received benefits, and only six (16.7\%) belonged to a self-help group. Of the $14(38.9 \%)$ who indicated that they drank alcohol, seven were drinking normal amounts, four had reduced their intake, and three were abstaining.

\section{Attribution scale}

Twenty two (61.1\%) felt that a viral onset was definitely a factor, and a further $10(27.8 \%)$ said that it might be a factor. Four (11.1\%) considered a current or ongoing infection was definitely a factor, with a further nine $(25.0 \%)$ thinking that it might be a factor. Only two (5.6\%) thought that food or other allergies were definitely the cause. In terms of psychological attributions, $13(36.1 \%)$ indicated that emotional upset was definitely a factor and $14(38.8 \%)$ thought that it might be a factor. Twelve (33.3\%) highlighted that school stresses were definitely a factor and eight (22.2\%) believed that the stress of relationships was definitely involved.

\section{Treatment}

Thirty four of 36 children (94.4\%) were prescribed at least one antidepressant, of which eight received a tricyclic antidepressant only and 26 received both a tricyclic antidepressant and a selective serotonin reuptake inhibitor. Thirty one $(86.1 \%)$ of the children and their families felt that they could tolerate the medication and 30 of them $(83.3 \%)$ believed that it helped them. Twenty nine $(80.6 \%)$ thought that the modified activity programme for mental activity was useful and 27 (75.0\%) believed that the modified activity programme for physical activity was useful.

\section{Patient satisfaction scale}

Highest scoring items included "having my illness taken seriously" (97.2\%), "changing how I manage the illness" (94.4\%), "getting support and encouragement" (94.4\%), "learning greater control over my symptoms" (86.1\%), and "adopting a step by step approach" (86.1\%). However, only 16 children $(44.4 \%)$ felt that they had a one-to-one relationship with their doctor.

\section{Outcomes}

\section{Global outcome measure}

For this measure, lower scores indicate good results (see table $3)$.

\section{Education}

In the week prior to first presentation at the clinic, the mean percentage of time spent at school was $29.9 \%$ (SD 33.9\%, range $0-100 \%)$. Fourteen children $(43.8 \%)$ informed us that they had not attended school at all in the week prior to presentation and only $12(37.5 \%)$ stated that they had attended for more than $50 \%$ of the full school week. Sixteen children and their families applied for home tuition, of which 13 received some. Worrying about returning to school was highlighted by $26(72.2 \%)$ children, and $22(61.1 \%)$ felt that their school had been supportive.

At the time of the survey, 32 of 36 of the children (88.9\%) were registered for full time education, of which 28 (77.8\%) 
Table 3 Outcome measures

\begin{tabular}{lllll}
\hline & Very or much better & Little, same, or worse & Mean (SD) & Range \\
\hline $\begin{array}{lllll}\text { Overall } \\
\text { Fatigue }\end{array}$ & $29(80.6 \%)$ & $7(19.4 \%)$ & $1.78(1.34)$ & $1-7$ \\
Handicap (restriction) & $28(77.8 \%)$ & $8(22.2 \%)$ & $2.03(1.14)$ & $1-6$ \\
& $28(77.8 \%)$ & $8(22.2 \%)$ & $1.82(1.09)$ & $1-6$ \\
\hline & $\begin{array}{l}\text { Very or moderately } \\
\text { satisfied }\end{array}$ & $\begin{array}{l}\text { Slightly satisfied or } \\
\text { dissatisfied }\end{array}$ & Mean (SD) & Range \\
\hline Satisfaction & $30(83.3 \%)$ & $6(16.7 \%)$ & $1.85(1.52)$ & $1-7$ \\
\hline & Very or moderately & $\begin{array}{l}\text { Useful or not } \\
\text { useful }\end{array}$ & Mean (SD) & Range \\
\hline useful & $6(16.7 \%)$ & $1.56(1.05)$ & $1-5$ \\
\hline & $30(83.3 \%)$ & & & \\
\hline
\end{tabular}

Table 4 Reported global improvement outcomes ${ }^{18}$

\begin{tabular}{llll}
\hline & $\begin{array}{l}\text { Normal or } \\
\text { improvement }\end{array}$ & $\begin{array}{l}\text { No change or } \\
\text { worse }\end{array}$ & Follow up duration \\
\hline Krilov et al $(1998)^{16}$ & $40 / 42(95.2 \%)$ & $2 / 42(4.8 \%)$ & Range 1-4 years \\
Feder et al $(1994)^{12}$ & $45 / 48(93.8 \%)$ & $3 / 48(6.2 \%)$ & Mean 3.8 years \\
Chalder et al $(2002)^{21}$ & $15 / 18(83.3 \%)$ & $3 / 18(16.7 \%)$ & Mean 6 months \\
Bell et al $(2001)^{41}$ & $28 / 35(80.0 \%)$ & $7 / 35(20.0 \%)$ & Average 13 years \\
Carter et al $(1995)^{13}$ & $24 / 31(77.4 \%)$ & $2 / 31(6.5 \%)$ & Median 16.9 months \\
Marshall et al $(1991)^{15}$ & $13 / 17(76.5 \%)$ & $2 / 17(11.8 \%)$ & Median 26 months \\
Garralda et al $(1999)^{40}$ & $17 / 25(68.0 \%)$ & $8 / 25(32.0 \%)$ & Mean 45.5 months \\
Smith et al $(1991)^{14}$ & $8 / 15(53.3 \%)$ & $7 / 15(46.7 \%)$ & Mean 18.4 months \\
\hline
\end{tabular}

did actually attend. Receiving treatment was therefore associated with increased school attendance, but in the absence of randomisation, this cannot be considered as causal.

At the follow up telephone call GCSE results were discussed (pass grades A-E). The median number of passes was 3 (range $0-10)$. Sixteen $(44.4 \%)$ achieved five or more passes and a further nine children (25\%) achieved 1-4 passes, although not all of these were at a single sitting. Unfortunately, 11 children $(30.6 \%)$ did not achieve any passes or did not even sit for their examinations. Twenty (55.6\%) remained in full time education and five $(13.9 \%)$ were in full time employment with a further one $(2.8 \%)$ in part time employment. Three $(8.3 \%)$ of the children were not working and were not in education, and there was missing data for the remaining seven (19.4\%) children.

\section{DISCUSSION}

This study was conducted in a GP specialist interest clinic in southeast England, and therefore differs from most other studies which report findings from tertiary centres. ${ }^{37}$ With a sample size of 36 children aged $11-18$ years, this study is large in comparison to most in the current literature.

Sociodemographic factors and the extent of general morbidity and functioning in the clinic were predominantly comparable to the literature..$^{13161938-40}$ As a cross sectional study, subjects were captured at different stages of treatment and this may explain why higher fatigue scores have been reported elsewhere. ${ }^{38}$ However, it has been further suggested that children and their parents might have unrealistic views of normative fatigue levels. ${ }^{20}$ Further our data showed that $75 \%$ reported the illness onset to be slow and uncertain in nature. Similarly another study $y^{41}$ has reported that $77 \%$ of their 35 patients had a gradual illness onset, and together these findings challenge the more commonly reported acute onset. ${ }^{12}$

For prognostic factors, we endorse that CFS in children be considered as an entity separate to that found in adults, ${ }^{6}$ as several common adult prognostic factors ${ }^{118}$ occur less frequently in children. However, a familial influence was seen in five subjects and others had a positive family psychiatric history. Furthermore, we found a high attribution to viral onset and lower attribution to psychological processes.

Overall the subjects found the treatment to be useful and were satisfied with it. However, it is of concern that over half of the children felt that they did not have a one-to-one relationship with their doctor and this is perhaps indicative of the presence of parents during all clinical appointments. While this is understandable, it may adversely impact on perceived patient autonomy for the adolescent.

Subjects also indicated that they were much better than they were before treatment as overall improvement or return to normal health was reported by $29 / 36$ (80.6\%) subjects and no change or worsening health was reported by the remaining seven $(19.4 \%)$. These findings are favourably comparable to those reported in the literature (see table 4). In general, outcome for children with CFS is favourable, 13151641 and several children resume normal activities. ${ }^{19}$

Notably, school attendance prior to treatment was low and nearly half the children were not attending school at all. These findings are worse than those previously reported. ${ }^{12} 131619$ One of the main difficulties here is that there is a lack of consistency across the literature in style and time parameters used for reporting school attendance and academic outcomes. In our study, home tutelage was received by 13 children; this in itself remains controversial, ${ }^{6}$ as most advocate a return to school as soon as possible. ${ }^{12}$ The issue of school refusal in children with CFS has been previously highlighted, ${ }^{3}$ and with 26 children worrying about returning to school, it is of concern that the return to school was possibly further prolonged. It has even been suggested that CFS could be conceptualised as a form of school refusal with the two conditions having essentially the same causes. ${ }^{6}$ In this study receiving treatment was associated with increased school attendance. However, from the follow up telephone call we identified that a third of the subjects either obtained no passes or did not even sit for their examinations. 


\section{Conclusion}

This study shows that in children and adolescents with CFS, patient characteristics in a GP specialist interest clinic setting are comparable to those seen in the more controlled setting of a tertiary referral research unit. Similarly, treatment methods used can be transferred into the real world with largely favourable outcomes, which are again comparable to the controlled setting. While there is clearly a need for better, more focused multidisciplinary rehabilitation, this study suggests a far more favourable prognosis for CFS than some of the popular literature. Given that the poor prognostic speculation ${ }^{27}$ can become a self-fulfilling prophecy by increasing helplessness, avoidance, and depression, we feel it is important to bring this more favourable prognosis to light.

In our study the most striking finding was perhaps that less than half of the children were attending school in the week prior to presentation in the clinic. The possible impact of treatment on school attendance was favourable but still with varying degrees of time spent in school. Comparison with the literature was in general only possible with smaller scale studies and the method of recording data on education varied considerably. In real life, the outcome of education is generally seen as the degree of success at national examinations (GCSEs) and entry to further education. These are rarely reported in the clinical literature. It is therefore suggested that consistency be obtained by development of standardised scales for school attendance and educational outcomes. Only then can the true impact of CFS on education be properly examined.

The main criticism of this study is that it used a cross sectional design and therefore relied on the responses to questionnaires as certain parameters were not detailed at first presentation. Despite this, this study supports the existing evidence that the prognosis for CFS in children and adolescents is generally good. However, the impact of the illness is significant, and this is perhaps most evident in terms of education.

\section{ACKNOWLEDGEMENTS}

Grateful thanks are extended to all participants and their families, Isama Smith for her administrative skills, Lakshika Tennakoon and Sophia Rabe-Hesketh for assistance with statistical analysis, Carmine Pariante and Paola Dazzan for their guidance, and particular thanks to David Anderson.

\section{Authors' affiliations}

M X Patel, T Chalder, S Wessely, Institute of Psychiatry and GKT School of Medicine, De Crespigny Park, London SE5 8AF, UK D G Smith, Malagay Barn, Church Road, West Tilbury Village, Essex RM18 8TU, UK

\section{REFERENCES}

1 Sharpe M, Archard L, Banatvala J, et al. Chronic fatigue syndrome: guidelines for research. J R. Soc Med 1991:84:118-21.

2 Royal Colleges of Physicians, Psychiatrists \& General Practitioners. Chronic fatigue syndrome. Report of a joint working group. London: Royal Colleges of Physicians, Psychiatrists \& General Practitioners, 1996.

3 Vereker $M$. Chronic fatigue syndrome: a joint paediatric-psychiatric approach. Arch Dis Child 1992:67:550-5.

4 Richards J, Smith F. Chronic fatigue syndrome in children and adolescents: general practitioners' experience of the problem and their views about its treatment. Psychiatr Bull 1998;22:203-6.

5 de Jong LW, Prins JB, Fiselier TJ, et al. [Chronic fatigue syndrome in young persons]. Nederlands Tijdschrift voor Geneeskunde 1997; 141:1513-16

6 Richards J. Chronic fatigue syndrome in children and adolescents: a review article. Clin Child Psychol Psychiatry 2000;5:31-51.
7 Lloyd A Hickie I, Boughton R, et al. Prevalence of chronic fatigue syndrome in an Australian population. Med J Aust 1990;153:522-8.

8 Jordan KM, Ayers PM, Jahn SC, et al. Prevalence of fatigue and chronic fatigue syndrome-like illness in children and adolescents. Journal of Chronic Fatigue Syndrome 2000;6:3-21.

9 Wessely S, Hotopf M, Sharpe M. CFS in children. Chronic fatigue and its syndromes. Oxford: Oxford University Press, 1998:284-97.

10 Straus SE. Caring for patients with chronic fatigue syndrome: conclusions in CMO's report are shaped by anecdote not evidence. BM 2002;324: 124-5.

11 Whiting P, Bagnall AM, Sowden AJ, et al. Interventions for the treatment and management of chronic fatigue syndrome: a systematic review. JAMA 2001:286:1360-8.

12 Feder H, Dworkin P, Orkin C. Outcome of 48 paediatric patients with chronic fatigue; a clinical experience. Arch Fam Med 1994;3:1049-55.

13 Carter B, Edwards J, Kronenberger W, et al. Case control study of chronic fatigue in paediatric patients. Pediatrics 1995:95:179-86.

14 Smith M, Mitchell J, Corey L, et al. Chronic fatigue in adolescents. Pediatrics 1991;88:195-201.

15 Marshall GS, Gesser RM, Yamanishi K, et al. Chronic fatigue in children: clinical features, Epstein-Barr virus and human herpes virus 6 serology and long term follow-up. Pediatr Infect Dis J 1991;10:287-90.

16 Krilov LR, Fisher M, Friedman SB, et al. Course and outcome of chronic fatigue in children and adolescents. Pediatrics 1998;102(2 pt 1):360-6

17 Bell D. Chronic fatigue syndrome in children. Journal of Chronic Fatigue Syndrome 1995:1:9-33.

18 Joyce J, Hotopf $M$, Wessely S. The prognosis of chronic fatigue and chronic fatigue syndrome: a systematic review. Q J Med 1997:90:223-33.

19 Rangel L, Garralda ME, Levin M, et al. The course of severe chronic fatigue syndrome in childhood. J R. Soc Med 2000;93:129-34.

20 Garralda ME, Rangel L. Childhood chronic fatigue syndrome. Am J Psychiatry 2001;158:1161.

21 Chalder T, Tong J, Deary V. Family cognitive therapy for chronic fatigue syndrome: an uncontrolled study. Arch Dis Child 2002;86:95-7.

22 Emslie GJ, Rush AJ, Weinberg WA, et al A double-blind, randomised placebo-controlled trial of fluoxetine in children and adolescents with depression. Arch Gen Psychiatry 1997;54:1031-7.

23 Moutarde O. Myalgic encephalopmyelitis in children. Lancet $2001 ; 357: 562$

24 Van Houdenhove, B. Does myalgic encephalopmyelitis exist? Lance 2001;357:1889

25 Speight N, Franklin A. Does myalgic encephalopmyelitis exist? Lancet 2001;357:1890.

26 Colby J. Study finds 12000 pupils may be suffering from ME. Sunday Times 5 June 1994

27 Franklin A. Children with ME: guidelines for school doctors and general practitioners. Stanford-le-Hope, Essex: ME Association, 1995.

28 Chalder T, Berelowitz G, Hirsch S, et al The development of a fatigue scale. J Psychosom Res1993;37:147-53.

29 Goldberg D The detection of psychiatric illness by questionnaire. London: Oxford University Press, 1972.

30 Marks I. Behavioural psychotherapy. Maudsley pocket book of clinical management. Bristol: Wright, 1986:37-9, 45-6

31 Zigmond AS, Snaith RP. The hospital anxiety and depression scale. Acta Psychiatr Scand 1983:67:361-70.

32 Marks IM, Mathews AM. Brief standard self-rating for phobic patients. Behav Res Treatment 1979;17:263-7.

33 Wittenborn JR, Buhler R. Somatic discomforts among depressed women Arch Gen Psychiatry 1979:36:465-71.

34 Deale A, Chalder T, Marks I, et al. Cognitive behaviour therapy for chronic fatigue syndrome: a randomised control trial. Am J Psychiatry 1997; 154:408-14.

35 Llewelyn SP, Hume WI. The patient's view of therapy. Br J Med Psychol 1979;52:29-35.

36 Office for National Statistics. Standard occupational classification Vols 1 and 2. London: The Stationery Office, 2000.

37 Euba R, Chalder T, Deale A, et al. Comparison of the characteristics of chronic fatigue syndrome in primary and tertiary care. $\mathrm{Br} J$ Psychiatry 1996;168:121-6.

38 Walford GA, Nelson WM, McCluskey DR. Fatigue, depression, and social adjustment in chronic fatigue syndrome. Arch Dis Child 1993;68:384-8.

39 Rowe KS. Double-blind randomised controlled trial to assess the efficacy of intravenous gammaglobulin for the management of chronic fatigue syndrome in adolescents. J Psychiatr Res 1997;31:133-47.

40 Garralda E, Rangel L, Levin $M$, et al. Psychiatric adjustment in adolescents with a history of chronic fatigue syndrome. J Am Acad Child Adolesc Psychiatry 1999;38:1515-21

41 Bell DS, Jordan K, Robinson M. Thirteen-year follow-up of children and adolescents with chronic fatigue syndrome. Pediatrics 2001:107:994-8. 